\title{
Spontaneous mid-trimester rupture of unscarred uterus
}

\author{
Kala K*, Jayashree Ashok Kumar, Rathipriya I, Jyoti Kamda
}

Department of Obstetrics \& Gynecology, MVJ Medical College, Hoskote, Bangalore, Karnataka, India

Received: 31 May 2014

Accepted: 10 June 2014

\author{
*Correspondence: \\ Dr. Kala K, \\ E-mail: kala.katti@gmail.com
}

(C) $2014 \mathrm{Kala} \mathrm{K}$ et al. This is an open-access article distributed under the terms of the Creative Commons Attribution Non-Commercial License, which permits unrestricted non-commercial use, distribution, and reproduction in any medium, provided the original work is properly cited.

\begin{abstract}
Spontaneous uterine rupture in early pregnancy and in unscarred uterus is an extremely rare event. It carries high maternal mortality and morbidity rate. We report a case of G2P1L1 with prior vaginal delivery who came with 21 weeks of gestation with pain abdomen, spotting per vagina and loss of fetal movements. During laparotomy entire amniotic sac was seen in peritoneal cavity. A rent of 6 to $7 \mathrm{~cm}$ was seen in left lateral wall of uterus which was repaired. Spontaneous rupture should be considered in women with acute pain abdomen even in absence of any risk factors regardless of gestational age and parity.
\end{abstract}

Keywords: Rupture of uterus, Unscarred, Spontaneous

\section{INTRODUCTION}

Spontaneous uterine rupture is a rare catastrophic event with high maternal mortality, morbidity and loss of future fertility as hysterectomy may be inevitable in many cases. Most of the spontaneous ruptures are seen during labour in term gestation and scarred uterus. Rupture of unscarred uterus is rare with incidence of 1 in 15000 deliveries and usually occurs in women of high parity. ${ }^{1}$ We report a rare case of spontaneous uterine rupture at 21 weeks gestation in a unscarred uterus.

\section{CASE REPORT}

A 22 years old G2P1L1 with prior vaginal delivery came with 21 weeks period of gestation with complaints of acute pain abdomen, loss of fetal movements and spotting per vagina since 2 hours and was referred from primary care centre to our hospital for ultrasound examination. Ultrasonography revealed that there was a rent in posterior wall of uterus and foetus was seen in peritoneal cavity with haemoperitoneum as appreciated in Figure 2. With immediate resuscitative measures patient was shifted to our side. On examination she was conscious, cooperative, pallor was present, pulse rate was 120 beats per minute, BP was 100/60 mmHg. Abdomen was mildly distended with tenderness in lower abdomen. The fetal parts were felt easily and fetal heart sounds were absent. Cervix was uneffaced and os was closed. There was no history of trauma or induction of abortion. She had a prior vaginal delivery at a hospital 1 and half year back. There was no history of prolonged labour or manual removal of placenta. There was no history of uterine curettage or uterine surgeries in past.

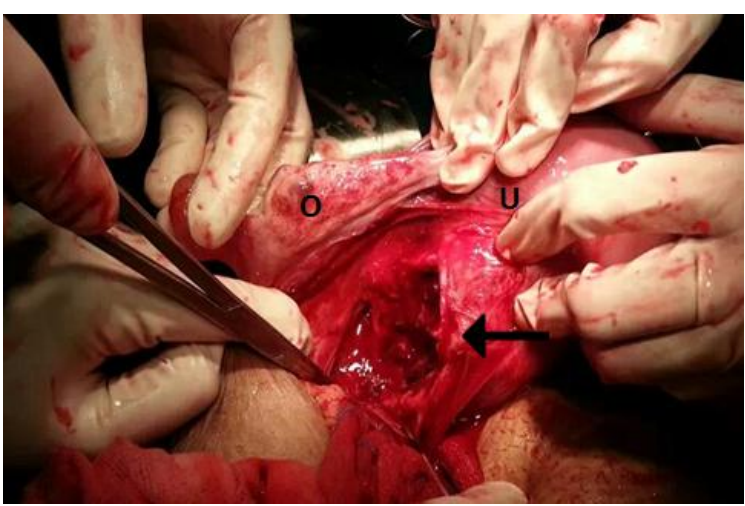

Figure 1: Intraoperative picture. O - Left ovary. UUterus. Arrow shows ruptured site. 
An emergency laparotomy revealed hemoperitoneum of 350 to $400 \mathrm{ml}$. An Intact amniotic sac with dead fetus of $400 \mathrm{gm}$ was seen in peritoneal cavity which was delivered out. Placenta was lying outside the uterus and appeared complete and normal. A vertical rent of 6 to 7 $\mathrm{cm}$ was seen on left lateral wall of uterus starting 3 to 4 $\mathrm{cm}$ below the round ligament. There was big a rent in adjacent broad ligament as appreciated in Figure 1. The rent was repaired in 2 layers. Bilateral tubes and ovaries were normal. There was no evidence of couvelaire uterus, uterine anomalies or endometriosis. Other abdominal organs were normal to the extent visualised. After achieving complete hemostasis abdomen was closed with intra-abdominal drain in situ. She received 2 units of blood transfusion. Intra-abdominal drain removed on $3^{\text {rd }}$ post op day. Her post op period was uneventful and was discharged on $8^{\text {th }}$ post op day.

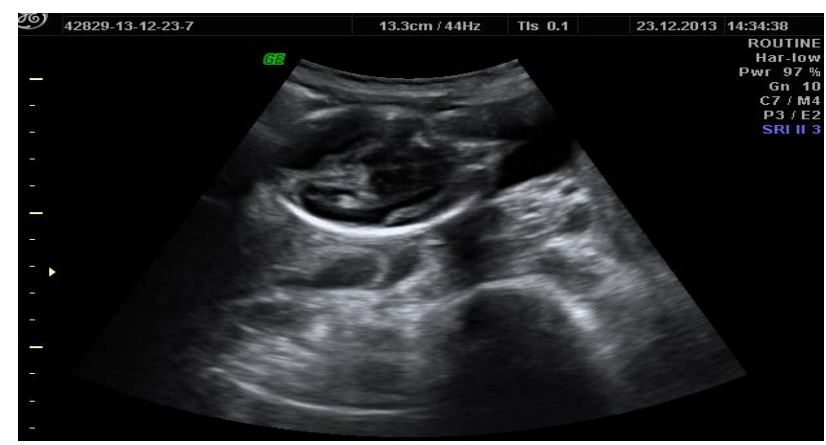

Figure 2: Ultrasound picture showing fetus freely lying in the abdominal cavity adjacent to bowel loops.

\section{DISCUSSION}

Spontaneous uterine rupture is a potentially life threatening event. It is secondary to risk factors like induction of labour, abnormal placentation, congenital uterine malformation, high birth order, prior uterine surgery or intra uterine intervention causing perforation. ${ }^{2}$

It is rare for an apparently uninjured or unscarred uterus to rupture in early pregnancy in the absence of any risk factors. There were no such risk factors, also there was no history of connective tissue disorder that is Ehler Danlos syndrome in our case. ${ }^{3}$ To our knowledge literature search revealed that this is the fourth reported case of spontaneous midtrimester rupture in absence of any risk factor. Retzke et al. reported spontaneous uterine rupture at 17 weeks gestation involving uterine fundus in a women with prior 3 vaginal deliveries. ${ }^{4}$ Sun et al. also reported similar case with fundal rupture at 17 weeks gestation in gravida $3 .{ }^{5}$ Kharakwal et al. reported rupture lateral wall of uterus at 20 weeks in G5P4. ${ }^{6}$ As compared to our case, rupture uterus in these case reports were seen in higher birth order. Kharakwal et al. reported that repeated child birth cause extreme weakness of uterine wall leading to uterine rupture. With this background information and in absence of history of connective tissue disorder, we thus speculate that subtle inherent weakness of uterine musculature which has become more pronounced in second pregnancy due to repeated stretching has led to rupture uterus in our case.

Maternal death is rare complication of rupture, though it is more common in developing countries occurring in unbooked cases and in women with an unscarred uterus. Prompt diagnosis early intervention has improved prognosis in our case.

\section{CONCLUSION}

Spontaneous uterine rupture should be considered in pregnant women even without risk factors, regardless of gestational age and parity. High index of suspicion, prompt diagnosis and early intervention significantly reduces maternal mortality and morbidity.

Funding: No funding sources

Conflict of interest: None declared

Ethical approval: Not required

\section{REFERENCES}

1. Miller DA, Paul RH. Rupture of unscarred uterus. Am J Obstet Gynecol. 1996;174:345.

2. Aboyeji AP, Ijaiya MD, Yahaya UR. Ruptured uterus: a study of 100 consecutive cases in Ilorin, Nigeria. J Obstet Gynecol Res. 2001;27:341-8.

3. Fransiska Malfai, Richard Wenstrup, Anne De Paepe. Ehlers-Danlos syndrome, classic type, 2007. Available http://www.ncbi.nlm.nih.gov/books/NBK1244. Accessed 18 August 2011.

4. Retzke JD, Book NM, Stempel LE. Spontaneous second trimester uterine rupture in the absence of known risk factors: a case report. J Reprod. 2009 Aug;54(8):525-8.

5. Sun HD, Su WH, Chang WH, Wen L, Huang BS, Wang PH. Rupture of a pregnant unscarred uterus in an early secondary trimester: a case report and brief review. J Obstet Gynecol Res. 2012 Feb;38(2):442-5.

6. Kharakwal S, Agarwal M. Spontaneous uterine rupture at 20 weeks gestation. J Obstet Gynecol India. 2009;59(3):246-8.

DOI: $10.5455 / 2320-1770$. ijrcog20140914

Cite this article as: Kala K, Kumar JA, Rathipriya

I, Kamda J. Spontaneous mid-trimester rupture of unscarred uterus. Int J Reprod Contracept Obstet Gynecol 2014;3:767-8. 